\title{
Honokiol synergizes chemotherapy drugs in multidrug resistant breast cancer cells via enhanced apoptosis and additional programmed necrotic death
}

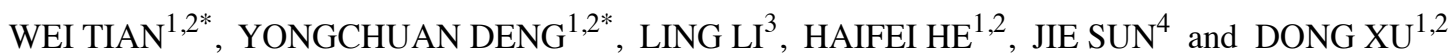 \\ ${ }^{1}$ Department of Surgical Oncology, ${ }^{2}$ Cancer Institute (The Key Laboratory of Cancer Prevention and Intervention, China \\ National Ministry of Education), The Second Affiliated Hospital, School of Medicine, Zhejiang University, Hangzhou, \\ Zhejiang 310009, P.R. China; ${ }^{3}$ Division of Stem Cell and Leukemia Research, City of Hope National Medical Center, \\ City of Hope, Duarte, CA 91010, USA; ${ }^{4}$ Zhejiang Youth College, Hangzhou, Zhejiang 310012, P.R. China
}

Received September 3, 2012; Accepted October 29, 2012

DOI: 10.3892/ijo.2012.1739

\begin{abstract}
Multidrug resistance (MDR) is a major challenge in cancer therapy. Apoptosis tolerance is one of the key mechanisms of MDR. Honokiol, a small-molecule pharmacologically active component, exhibits competent cytotoxicity in a variety of human cancer cells through apoptosis and other forms of programmed cell death (such as programmed necrosis). Although much work has been done on its antitumor effects, little attention has been paid on systemic evaluation of efficacy of honokiol combined with other chemotherapeutic agents, especially in drug-resistant cell lines. Here, we systematically and quantitatively assess its combinational effect with different chemotherapeutic agents using the combination index (CI) equation. We found that honokiol synergized with chemotherapeutic agents both in sensitive and resistant, solid and non-solid (MCF-7, HL-60, MCF-7/ADR and HL-60/ADR) cell lines. Honokiol (40 $\mu \mathrm{g} / \mathrm{ml})$ induced necrotic cell death in MCF-7/ADR cells with characterized morphological and biochemical features. Co-incubation with honokiol and etoposide (VP-16) activated a complex death modality, which was composed of necrotic cell death and apoptosis. This dual-death pathway was shut down when pretreated with pan-caspase inhibitor (z-VAD-fmk) and cyclophilin D inhibitor (cyclosporin A). Western blot analysis results proved that honokiol also enhanced VP-16-induced apoptosis potentially via blocking nuclear factor- $\kappa \mathrm{B}(\mathrm{NF}-\kappa \mathrm{B})$ activation. Our data for the first time quantitatively demonstrate that honokiol synergizes frequently-used chemotherapeutic agents via enhanced apoptosis and additional programmed
\end{abstract}

Correspondence to: $\mathrm{Dr}$ Dong $\mathrm{Xu}$, Department of Surgical Oncology, The Second Affiliated Hospital, School of Medicine, Zhejiang University, no. 88 Jiefang Road, Hangzhou, Zhejiang 310009, P.R. China

E-mail: xudongzju@zju.edu.cn

*Contributed equally

Key words: honokiol, breast cancer, multidrug drug resistance, apoptosis, programmed necrotic death necrotic death. These findings indicate a promising way to circumvent MDR and apoptosis tolerance.

\section{Introduction}

Multidrug drug resistance (MDR) is defined as concomitant existing resistance to several structurally and functionally diverse drugs (1-4). It is a very complicated and dynamical system composed of diverse cellular factors and signal transduction pathways. Major participants of MDR include drug transporter-mediated increased efflux of anticancer agents, evasion of drug-induced apoptosis and others (3,5). Most current chemotherapeutic drugs are substrates or inducers of drug transporters and induce cytotoxicity through apoptosis (1). Basing on this concept, recent research mainly focused on exploring and developing drugs reversing transport-mediated MDR and reactivating apoptosis. But most of these drugs failed to show clinical efficacy $(6,7)$. Since MDR is modulated by a very complicated system, simply inhibiting one or two signal pathways or regulators can not succeed in overcoming it (1). Beside classical type of programmed cell death (apoptosis), other programmed death modalities exist, such as autophagy and programmed necrotic death (necroptosis) (8). Gradually increasing evidence demonstrates cancer cells resistant to current chemotherapeutic drugs are sensitive to drug-induced programmed necrotic death (9-11). Accordingly, contemporaneously activating multiple types of programmed cell death by multi-drug treatment regimen is a promising option to circumvent MDR, especially apoptosis tolerance.

Honokiol (HNK) is a small molecule isolated from Chinese traditional medicinal herb Houpu with various pharmacological activities. Among all its medicinal applications, antitumor activity is most extensively studied. Honokiol-induced apoptosis, including caspase-dependent and -independent apoptosis (12), is the most widely investigated and fundamental mechanism of its antitumor activity. Besides, other cell death forms, such as programmed necrotic cell death (9) and paraptosis (13), are also induced by honokiol at certain doses. Our group is devoted to mechanical research on antitumor effects of honokiol. Previous work of our group demonstrated that honokiol induced apop- 
tosis in human colorectal carcinoma RKO cells associated with caspase cascade $(14,15)$. Besides, we evaluated honokiol potentiated cytotoxic effect of adriamycin through downregulation of P-gycoprotein (P-gp) in drug resistant breast carcinoma cell line MCF-7/ADR (2). Further, our subsequent study first reported that honokiol induced a distinct programmed cell death modality, programmed necrotic death (9), initiating new insights and greatly expanding the cognition of its antitumor activity.

Most of the therapy studies concerning combination effect of two or more anticancer drugs only focus on 'therapeutic synergy'. They lack quantitative data perhaps of composed of pure synergism, additive effect or even moderate antagonism. Although literature is available on antitumor effects of honokiol, little attention has been paid on systemic and quantitative evaluation of efficacy combining honokiol with chemotherapeutic agents, especially in drug resistant cell lines. We assessed the possible combination effects between honokiol and other chemotherapeutic agents and explored optimal synergistic drug combinations through a quantitative analysis method (16). Mechanisms of the synergistic activation are mainly evaluated in the present study.

\section{Materials and methods}

Reagents and chemicals. Honokiol was purchased from the National Institute for the Control of Pharmaceutical and Biological Products (Beijing, China) with $>99 \%$ purity. Honokiol power was dissolved in dimethyl sulfoxide (DMSO) at $20 \mathrm{mg} /$ $\mathrm{ml}$ solution and stored at $-20^{\circ} \mathrm{C}$. RPMI-1640, fetal bovine serum (FBS), and $0.25 \%$ trypsin were purchased from Gibco-BRL (Invitrogen Co., Grand Island, NY, USA). Cyclosporin A (CsA), etoposide (VP-16) and MTT power were purchased from Sigma-Aldrich (St. Louis, MO, USA). Doxorubicin (ADM) and daunorubicin (DNR) were purchased from Pfizer (Actavis Italy S.p.A., Nerviano, MI, Italy). Paclitaxel (taxol) was purchased from Bristol-Myers Squibb (Princeton, NJ, USA). Pan-caspase inhibitor z-VAD-fmk was from Beyotime Institute of Biotechnology (Shanghai, China). Annexin V-FITC/PI kit was purchased from Sigma-Aldrich. Apotosis DNA Ladder Detection Kit was from KeyGen Biotech (Nanjing, China).

Cell culture. Human breast carcinoma cell line MCF-7 and acute promyelocytic leukemia cell line HL-60 were maintained in RPMI-1640 supplemented with 10\% FBS. Parallel multidrug resistant cell lines MCF-7/ADR and HL-60/ADR were developed as reported previously (2) and maintained in RPMI-1640 with $1 \mu \mathrm{g} / \mathrm{ml}$ and $100 \mathrm{ng} / \mathrm{ml} \mathrm{ADM}$, respectively. Various cells were grown in a humidified $\mathrm{CO}_{2}$ incubator at $37^{\circ} \mathrm{C}$ and maintained in exponential growth.

Evaluation of drug combination index. Cells were plated in 96-well micro-titer plates of 4,000-8,000 cells/well. After incubation overnight, cells were incubated with drug-free medium, honokiol or chemotherapeutic agent alone or combination of honokiol and chemotherapeutic agent with different rational concentrations. DMSO according to the highest drug concentration served as control. Quadruple wells were prepared for each drug concentration. After $48 \mathrm{~h}$, MTT assays were performed as previously described (2). Viabilities were normalized to untreated samples. Combination index determinations were performed basing on the method of Chou and Talalay (16). Various cytotoxicity levels of the component drugs and combinations were calculated according to equation 1. Combination index values were calculated using equation 2 at each level of cytotoxicity.

$$
\mathrm{D}_{1-\mathrm{FA}}=\mathrm{D}_{\mathrm{x}}[\mathrm{FA} /(1-\mathrm{FA})]^{1 / \mathrm{m}}
$$

Combination index $(\mathrm{CI})=(\mathrm{D})_{1} /\left(\mathrm{D}_{1-\mathrm{FA}}\right)_{1}+$ $(\mathrm{D})_{2} /\left(\mathrm{D}_{1-\mathrm{FA}}\right)_{2}+\alpha(\mathrm{D})_{1}(\mathrm{D})_{2} /\left(\mathrm{D}_{1-\mathrm{FA}}\right)_{1}\left(\mathrm{D}_{1-\mathrm{FA}}\right)_{2}$

In the above equations, ' $\mathrm{m}$ ' (stood for sigmoidity) and $\mathrm{D}_{\mathrm{x}}$ (is the $\mathrm{IC}_{50}$ for $50 \%$ growth inhibition) were calculated by transforming concentration-effect data to a logarithmic scale. FA stood for the growth-inhibitory effect of each drug. (D) ${ }_{1}$ and (D) $)_{2}$ represented the doses of the combination required to produce survival (1-FA), while $\left(\mathrm{D}_{1-\mathrm{FA}}\right)_{1}$ and $\left(\mathrm{D}_{1-\mathrm{FA}}\right)_{2}$ stood for the concentrations of the component drugs required to produce survival (1-FA), $\alpha=1$ for mutually nonexclusive drugs (17). In analysis, degree of combination effect was determined from the combination index (CI) as follows: $\mathrm{CI}>1$, antagonism; $\mathrm{CI}=1$, additivity; $\mathrm{CI}<1$, synergism.

Evaluation of dose reduction index (DRI). Two concentrations of honokiol were chosen for each cell line in the evaluation of DRI, which would produce $90-95 \%\left(\mathrm{HNK}^{1}\right)$ and $70-80 \%$ $\left(\mathrm{HNK}^{2}\right)$ cell survival, respectively. The exact doses of $\mathrm{HNK}^{1}$ and $\mathrm{HNK}^{2}$ for each cell line are shown in Table III. After incubation overnight, cells plated in 96-well plates were treated with different chemotherapeutic agents in concentrationgradient combined with either blank control, $\mathrm{HNK}^{1}$ or $\mathrm{HNK}^{2}$. After $48 \mathrm{~h}, \mathrm{MTT}$ assays were performed. $\mathrm{IC}_{50}$ was calculated by transforming the concentration-effect data to a logarithmic scale. DRI values were determined using equation 3 . $\left(\mathrm{IC}_{50}\right)_{1}$ and $\left(\mathrm{IC}_{50}\right)_{2}$ stood for $\mathrm{IC}_{50}$ of a chemotherapeutic agent without or with honokiol, respectively.

$$
\text { Dose Reduction Index }(\mathrm{DRI})=\left(\mathrm{IC}_{50}\right)_{1} /\left(\mathrm{IC}_{50}\right)_{2}
$$

Cell viability assay. MCF-7/ADR cells were treated with $40 \mu \mathrm{g} / \mathrm{ml}$ honokiol, $100 \mu \mathrm{g} / \mathrm{ml} \mathrm{VP-16}$, or combination, respectively. After 6-h incubation, MTT assay was performed to determine cell viability.

Flow cytometric analysis for apoptosis. MCF-7/ADR cells were cultured in 6-well culture plates at $8 \times 10^{5} /$ well in $2 \mathrm{ml}$ media for $24 \mathrm{~h}$ and treated with $0.1 \%$ DMSO (vehicle control), $40 \mu \mathrm{g} / \mathrm{ml}$ honokiol, $100 \mu \mathrm{g} / \mathrm{ml} \mathrm{VP-16}$, or combination for $6 \mathrm{~h}$. Apoptotic rates were analyzed by flow cytometry using Annexin V-FITC/PI kit according to the manufacturer's instructions. The differentiation among early apoptotic cells, necrotic cells and viable cells were detected as follows: Annexin V positive and PI negative; Annexin V positive and PI positive; and Annexin V negative and PI negative, according to a previous report (9). The experiments were done in triplicate and similar results were obtained in three different experimental setups.

Electron microscopy detection of cell death. Cells were seeded and treated as described above for flow cytometric analysis for apoptosis. The exact procedure was processed according to previously reported methods (9). 
Table I. CI values in sensitive and resistant breast cancer cell lines.

\begin{tabular}{lccccccr}
\hline & \multicolumn{3}{c}{ MCF-7/ADR } & & \multicolumn{3}{c}{ MCF-7 } \\
\cline { 2 - 3 } & $\mathrm{CI}_{50}$ & $\mathrm{CI}_{75}$ & $\mathrm{CI}_{85}$ & & $\mathrm{CI}_{50}$ & $\mathrm{CI}_{75}$ & $\mathrm{CI}_{85}$ \\
\hline ADM+HNK & 0.88257 & 0.83857 & 0.79670 & & 0.96022 & 0.89845 & 0.79886 \\
VP-16+HNK & 0.55658 & 0.79018 & 0.92997 & & 1.49818 & 1.54569 & 1.48601 \\
TAX+HNK & 0.94141 & 0.97348 & 1.11481 & & 0.72882 & 0.89689 & 1.08079 \\
\hline
\end{tabular}

$\mathrm{CI}_{50}, \mathrm{CI}_{75}$ and $\mathrm{CI}_{85}$ refer to $\mathrm{CI}$ values at $\mathrm{IC}_{50}, \mathrm{IC}_{75}$ and $\mathrm{IC}_{85}$, respectively. $\mathrm{Cl}>1$, antagonism; $\mathrm{Cl}=1$, additivity; $\mathrm{Cl}<1$, synergism.

Table II. CI values in sensitive and resistant leukemia cell lines.

\begin{tabular}{|c|c|c|c|c|c|c|}
\hline & \multicolumn{3}{|c|}{ HL-60/ADR } & \multicolumn{3}{|c|}{ HL-60 } \\
\hline & $\mathrm{CI}_{50}$ & $\mathrm{CI}_{75}$ & $\mathrm{CI}_{85}$ & $\mathrm{CI}_{50}$ & $\mathrm{CI}_{75}$ & $\mathrm{CI}_{85}$ \\
\hline DNR+HNK & 0.74049 & 0.80216 & 0.84755 & 0.88873 & 0.91171 & 0.91009 \\
\hline
\end{tabular}

DNA ladder detection. Cells were seeded and treated as indicated above. After treatment, cells were collected and washed twice with chilled PBS. Afterwards, DNA gel electrophoresis was carried out after DNA extraction according to the manufacturer's instructions of DNA Ladder Detection kit. Experimental conditions were tested in triplicate and similar results were obtained at least three times.

Western blot analysis for $N F-\kappa B$ translocation detection. For detection of nuclear factor- $\kappa \mathrm{B}(\mathrm{NF}-\kappa \mathrm{B})$ proteins, cells were treated with $0.1 \%$ DMSO (vehicle control), $40 \mu \mathrm{g} / \mathrm{ml}$ honokiol, $100 \mu \mathrm{g} / \mathrm{ml} \mathrm{VP}-16$, or combination, respectively, for $2 \mathrm{~h}$. Cells were harvested for isolation of nuclear and cytoplasm extracts using Nuclear Extract Kit (Activ Motif, Carlsbad, CA, USA). The concentration of each protein was then determined by the standard BCA protein assay. About $40 \mu \mathrm{g}$ of each sample was loaded in gel for immunoblot assay according to standard protocol. After cell lysate preparation, proteins were applied to a $10 \%$ SDS-PAGE and electro-transferred to a nitrocellulose membrane. Blots were probed by the proper primary antibodies (mouse monoclonal anti-human NF- $\mathrm{BB}$ and rabbit polyclonal anti-human lamin-B and $\alpha$-tubulin (Cell Signaling Technology Inc., Danvers, MA, USA) overnight at $4^{\circ} \mathrm{C}$ and then exposed to secondary antibodies (HRP-conjugated anti-rabbit IgG (Santa Cruz Biotechnology, Santa Cruz, CA, USA) for $2 \mathrm{~h}$. Visualization was finally detected by chemiluminescence using ECL Plus Western Blotting Substrate (Thermo Fisher Scientific, Rockford, IL, USA). Lamin B and $\alpha$-tubulin was used to ensure equal loading of protein on the gel. Densitometry was performed to quantify the relative expression levels of NF- $\mathrm{kB}$ protein.

Statistical analysis. The data represent mean \pm SD from three independent experiments. Student's t-test was used for comparison between in vitro responses to different drugs. All analyses were two-tailed.

\section{Results}

Combination effects of honokiol with different chemotherapeutic agents at rational combination doses in different cell lines. We used multiple drug effect analysis method of Chou and Talalay (16) to determine the nature of interaction between honokiol and various chemotherapeutic agents. Four different anticancer drugs (etoposide, doxorubicine, taxol and daunorubicin), commonly used in the treatment of breast cancer and leukemia were selected in the present study. Human breast carcinoma cell line MCF-7, acute promyelocytic leukemia cell line HL-60 and parallel multidrug resistant cell lines MCF-7/ADR, HL-60/ADR were treated with serial dilutions of honokiol and various chemotherapeutic agents at fixed ratios spanning the $\mathrm{IC}_{50}$ of each drug. Combination index values at different dose-effect levels were calculated on the basis of parameters derived from effect plots of honokiol alone, the chemotherapeutic agent alone and the combination of the two. $\mathrm{CI}<1, \mathrm{CI}=1$ and $\mathrm{CI}>1$ indicate synergism, additivity and antagonism effect, respectively. Honokiol synergistically enhanced cytotoxicity of ADM and VP-16 in MCF-7/ADR as the CI values were $<1.0$ at all dose-effect levels (50, 75 and 85\% inhibition rate) (Table I, Fig. 1). CI values for MCF-7/ADR at $\mathrm{IC}_{50}$ and $\mathrm{IC}_{75}$ were $<1.0$ for taxol indicating a synergistic interaction, but $\mathrm{CI}_{85}$ indicated antagonism (Table I, Fig. 1). The interaction for MCF-7 was synergism between honokiol and ADM at all dose-effect levels, whereas antagonism between honokiol and VP-16. It was synergism between honokiol and taxol for MCF-7 at $\mathrm{IC}_{50}$ and $\mathrm{IC}_{75}$ but antagonism at $\mathrm{IC}_{85}$ (Table I, Fig. 1). Honokiol and daunorubicin (DNR) had synergistic interactions against HL-60 and HL-60/ ADR (Table II, Fig. 1).

To compare combination effects among different groups, we calculated the mean $\mathrm{CI}$ values [mean $\mathrm{CI}=\left(\mathrm{CI}_{50}+\mathrm{CI}_{75}+\mathrm{CI}_{85}\right) / 3$ ] (Fig. 1B). Honokiol synergized most chemotherapeutic agents both in P-gp (MCF-7/ADR) and MRP1 (HL-60/ADR) medi- 


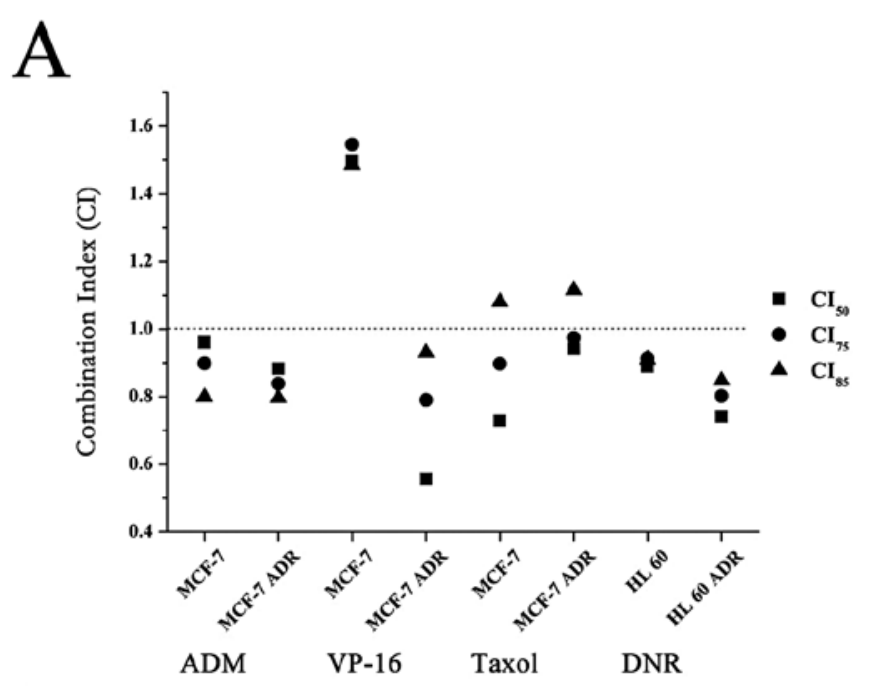

B

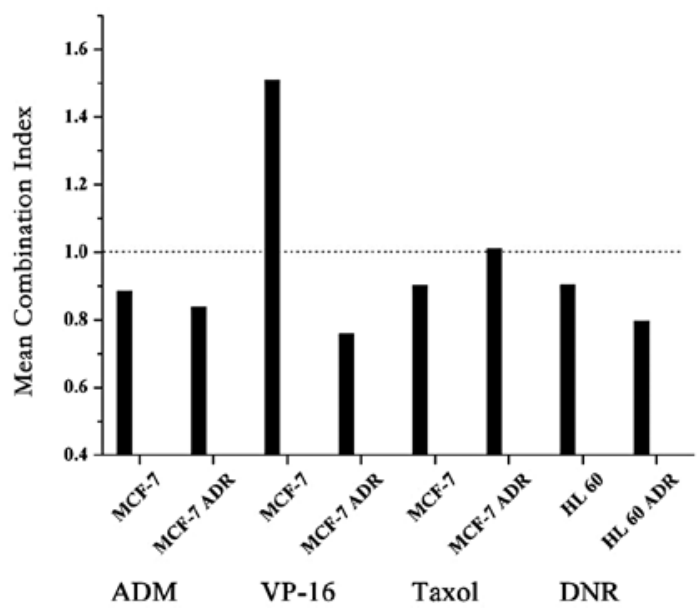

Figure 1. Combination effects of honokiol with different chemotherapeutic agents at rational combination doses in different cell lines. After treatment for $48 \mathrm{~h}$, we evaluated (A) the combination index of honokiol with each chemotherapeutic agent at 50,75 and 85\% inhibitory levels, respectively and (B) their average combination index. Degree of combination effect was determined as follows: $\mathrm{CI}>1$, antagonism; $\mathrm{CI}=1$, additivity; $\mathrm{CI}<1$, synergism.

ated MDR cancer cells. Surprisingly, the most marked mean CI values existed in honokiol plus VP-16 combination in MCF-7/ ADR and parallel cell line MCF-7, which indicated conflicting effects.

Dose reduction of chemotherapeutic drugs after combined treatment with honokiol. DRI parameters represent the order of magnitude of dose reduction which is determined from the relative proportions between the dose of combination and each drug alone at 50\% inhibitory effect. Cell viabilities of each cancer cell line after treatments of the two given doses of honokiol ( $\mathrm{HNK}^{1}$ and $\mathrm{HNK}^{2}$, exact doses are shown in Table III) alone were $90-95$ and $70-80 \%$, respectively. On the other hand, $\mathrm{HNK}^{1}$ and $\mathrm{HNK}^{2}$ do no harm to human normal cells, such as normal PBMC (18). Dose-response curves demonstrated dose-dependent growth-inhibition by a single chemotherapeutic agent or combined with a given dose of
Table III. Stated doses of honokiol for evaluation of dose reduction index.

\begin{tabular}{lcc}
\hline & $\mathrm{HNK}^{1}(\mu \mathrm{g} / \mathrm{ml})$ & $\mathrm{HNK}^{2}(\mu \mathrm{g} / \mathrm{ml})$ \\
\hline HL-60 & 4 & 5 \\
HL-60/ADR & 4 & 5 \\
MCF-7 & 12.5 & 13.5 \\
MCF-7/ADR & 11.5 & 12.5
\end{tabular}

The two concentrations of honokiol were chosen for each cell line in the evaluation of DRI, which would produce $90-95 \%\left(\mathrm{HNK}^{1}\right)$ and $70-80 \%\left(\mathrm{HNK}^{2}\right)$ cells survival, respectively.

Honokiol $\left(\mathrm{HNK}^{1}\right.$ or $\mathrm{HNK}^{2}$ ) in all cell lines (Fig. 2). $\mathrm{IC}_{50}$ was calculated by transforming the concentration-effect data to a logarithmic scale. Based on the $\mathrm{IC}_{50} \mathrm{~s}$, DRI for each chemotherapeutic agent was determined using equation 3 .

Conspicuous DRI values from 1.85 to 17.32 were observed in the combination setting compared with chemotherapeutic agents alone except that of MCF-7 treated with VP-16 (Table IV). A dose of $12.5 \mu \mathrm{g} / \mathrm{ml}$ honokiol had no synergistic effect in combination with VP-16 in MCF-7 cell line as the DRI value was -1.20 (Table IVD). The given doses of honokiol had greater dose-reducing effects in settings of VP-16 treatment in MCF-7/ADR than in MCF-7, and of DNR in HL-60/ADR than in HL-60 (Table IVB and D).

Above results indicated that in most combination groups calculated DRI values were $>1$, whose trendency coincided well with CI values. Conspicuously, the most prominent DRI (17.32) was measured in honokiol plus VP-16 combination in MCF-7/ADR cells, which matched exactly to the lowest $\mathrm{CI}$ arisen group (as shown in the section: Combination effects of honokiol with different chemotherapeutic agents at rational combination doses in different cell lines). Accordingly, honokiol plus VP-16 combination treatment in MCF-7/ADR was chosen as representative in assessing synergetic mechanism.

Cytotoxicity of honokiol plus VP-16 at highest rational doses towards multidrug resistant MCF-7/ADR cells. Based on the above results, we further tested the potential synergistic effect of honokiol on VP-16 induced MCF-7/ADR cell death at highest rational doses. Concentration of honokiol used in the following experiment was $40 \mu \mathrm{g} / \mathrm{ml}$, and corresponding rational concentration of VP-16 was $100 \mu \mathrm{g} / \mathrm{ml}$. After 6-h incubation, cell viabilities after $100 \mu \mathrm{g} / \mathrm{ml} \mathrm{VP}-16,40 \mu \mathrm{g} /$ $\mathrm{ml}$ honokiol, or combination treatment were $82.33 \pm 3.73$, $56.21 \pm 2.97$ and $48.18 \pm 1.38 \%$, respectively. VP-16 alone only slightly affected cell viability of MCF-7/ADR. Honokiol plus VP-16 had dramatically enhanced cell toxicity compared to that of VP-16 or honokiol alone $(\mathrm{P}<0.005)$ (Fig. 3).

Honokiol induces programmed necrotic cell death in MCF-7/ADR cells, which is reversed by cyclosporin A. Honokiol $(40 \mu \mathrm{g} / \mathrm{ml})$ induces programmed cell death with necrotic characteristics in MCF-7 cells as we reported previously (9). We hypothesized honokiol at the same concentration could primarily induce programmed necrotic 
MCF-7

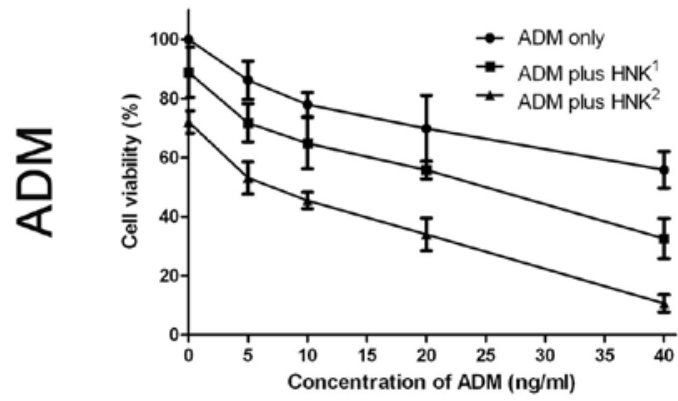

MCF-7

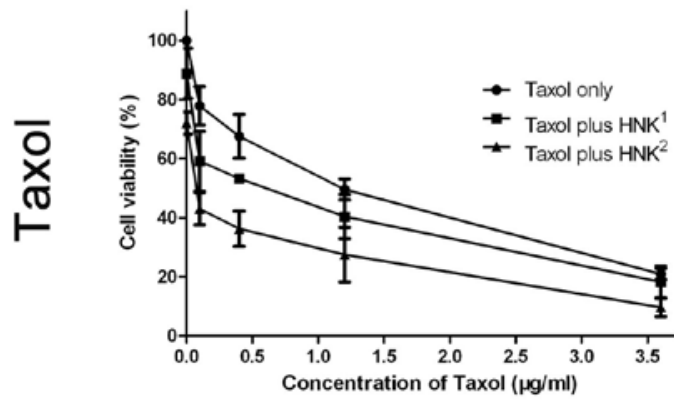

MCF-7

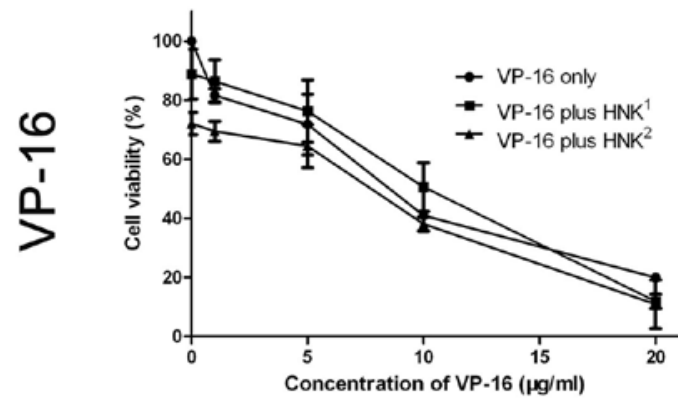

HL-60

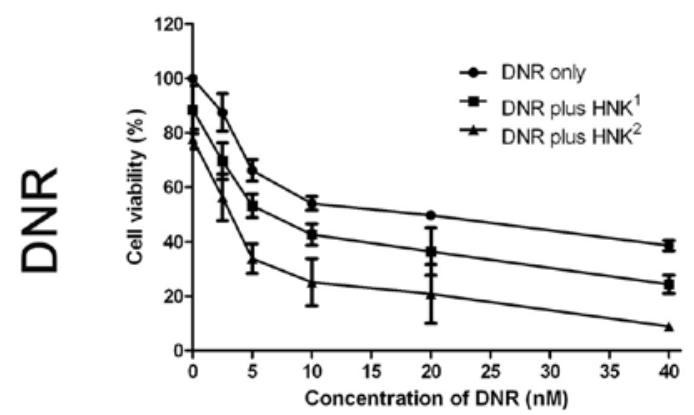

MCF-7/ADR

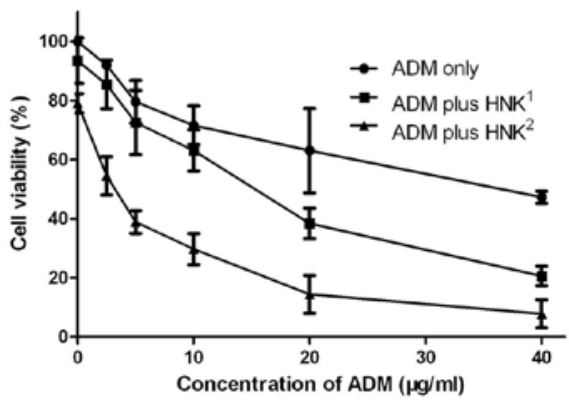

MCF-7/ADR

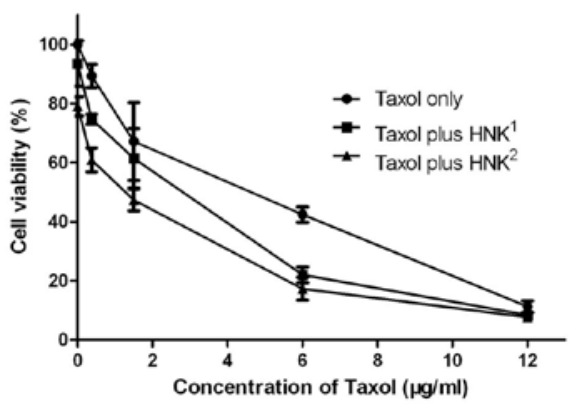

MCF-7/ADR

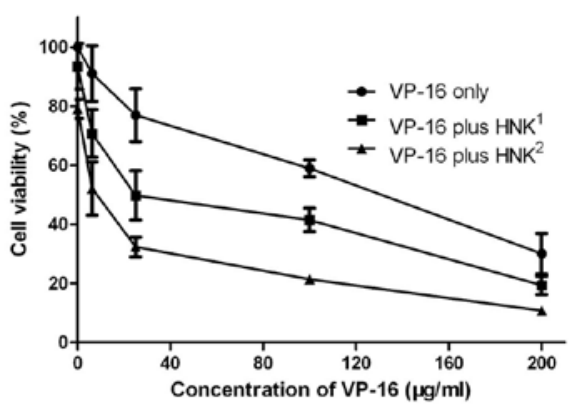

HL-60/ADR

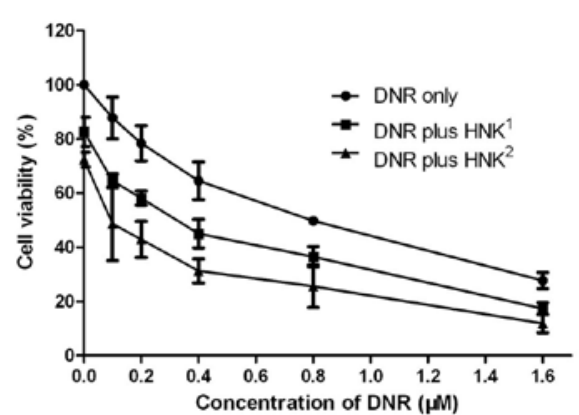

Figure 2. Cooperative effects of honokiol at given dose with different chemotherapeutic agents in concentration-gradients. The exact concentrations of honokiol in each cell line are shown in Table I. Cell viabilities were analyzed by MTT assays. These results were representative of three independent experiments. The values are shown as mean $\pm \mathrm{SD}$. 
Table IV. DRI values for combinations of given dose of honokiol with different chemotherapeutic agents.

A,

\begin{tabular}{|c|c|c|c|c|c|}
\hline & \multicolumn{3}{|c|}{$\mathrm{IC}_{50}(\mu \mathrm{g} / \mathrm{ml})$} & \multicolumn{2}{|c|}{ DRI } \\
\hline & ADM alone & Plus HNK ${ }^{1}$ & Plus HNK ${ }^{2}$ & Plus HNK ${ }^{1}$ & Plus $\mathrm{HNK}^{2}$ \\
\hline MCF-7 & 0.055 & 0.019 & 0.008 & 2.89 & 6.8 \\
\hline MCF-7/ADR & 43.10 & 20.80 & 5.40 & 2.07 & 7.98 \\
\hline
\end{tabular}

$\mathrm{B}$,

\begin{tabular}{lccccc}
\hline & & $\mathrm{IC}_{50}(\mu \mathrm{g} / \mathrm{ml})$ & & DRI \\
\cline { 2 - 5 } & VP-16 alone & Plus HNK & Plus HNK $^{2}$ & & Plus HNK $^{1}$ \\
\hline MCF-7 & 8.54 & 10.22 & 7.30 & -1.20 & Plus HNK $^{2}$ \\
MCF-7/ADR & 124.34 & 20.54 & 7.18 & 6.05 & 1.17 \\
\hline
\end{tabular}

C,

\begin{tabular}{|c|c|c|c|c|c|}
\hline & \multicolumn{3}{|c|}{$\mathrm{IC}_{50}(\mu \mathrm{g} / \mathrm{ml})$} & \multicolumn{2}{|c|}{ DRI } \\
\hline & Taxol alone & Plus HNK ${ }^{1}$ & Plus HNK ${ }^{2}$ & Plus HNK ${ }^{1}$ & Plus HNK ${ }^{2}$ \\
\hline MCF-7 & 0.99 & 0.26 & 0.09 & 3.81 & 11.00 \\
\hline MCF-7/ADR & 3.87 & 2.09 & 1.10 & 1.85 & 3.52 \\
\hline
\end{tabular}

D,

\begin{tabular}{|c|c|c|c|c|c|}
\hline & \multicolumn{3}{|c|}{$\mathrm{IC}_{50}(\mu \mathrm{g} / \mathrm{ml})$} & \multicolumn{2}{|c|}{ DRI } \\
\hline & DNR alone & Plus HNK ${ }^{1}$ & Plus HNK ${ }^{2}$ & Plus HNK ${ }^{1}$ & Plus $\mathrm{HNK}^{2}$ \\
\hline HL-60 & 0.0142 & 0.0069 & 0.0032 & 2.06 & 4.44 \\
\hline HL-60/ADR & 0.72 & 0.27 & 0.08 & 2.67 & 9.00 \\
\hline
\end{tabular}

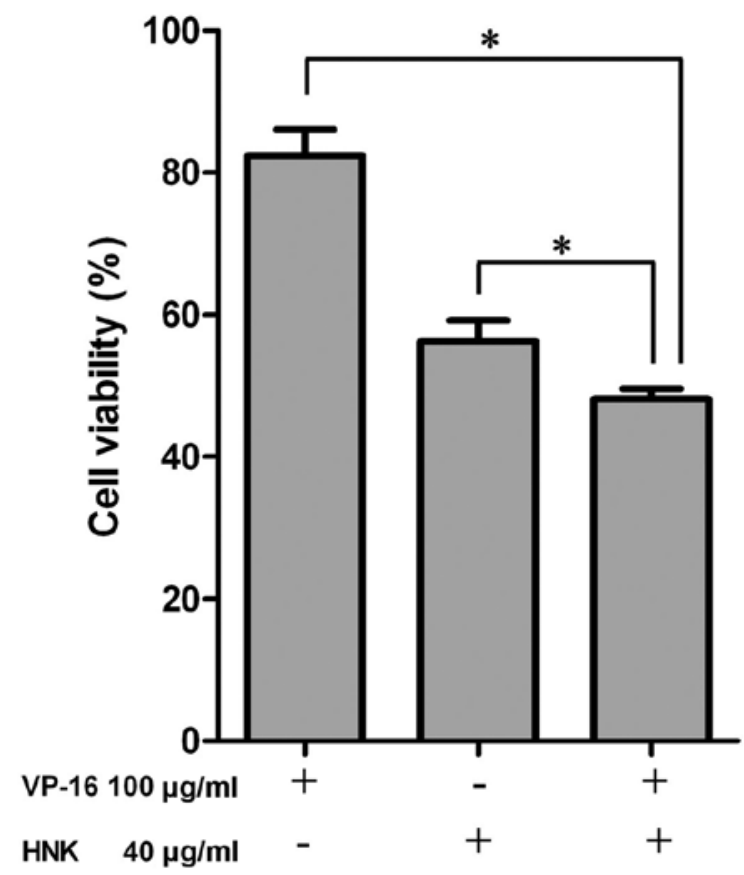

cell death in the parallel drug resistant cell line MCF-7/ADR. This hypothesis was supported by results of DNA ladder detection as only clumping degradation of nuclear DNA was detected after 6 -h incubation with $40 \mu \mathrm{g} / \mathrm{ml}$ honokiol (Fig. 4). Compared with normal cells (Fig. 5A) and $100 \mu \mathrm{g} / \mathrm{ml}$ VP-16-treated cells (Fig. 5B), electron microscopy morphological manifestations revealed majority of cells underwent necrotic cell death characterized manifestations of increased cell volume due to swelling of cytoplasmic organelles, dilatation of mitochondria and endoplasmic reticulum, vacuoles and nuclear modifications (Fig. 5C). Not surprisingly, flow cytometry demonstrated that honokiol alone induced a dominant death characterized by loss of plasma membrane

Figure 3. Cytotoxicity of honokiol plus VP-16 at highest rational doses towards MCF-7/ADR cells. After treatment with honokiol, VP-16 or combination of drugs for $6 \mathrm{~h}$, cell viabilities were analyzed by MTT assays. Cytotoxicity induced by combination drugs was enhanced compared with each single drug. These results were representative of three independent experiments. The values shown are the mean $\pm \mathrm{SD}$. ${ }^{*} \mathrm{P}<0.001$ vs. VP-16- or honokiol-treated cells. 


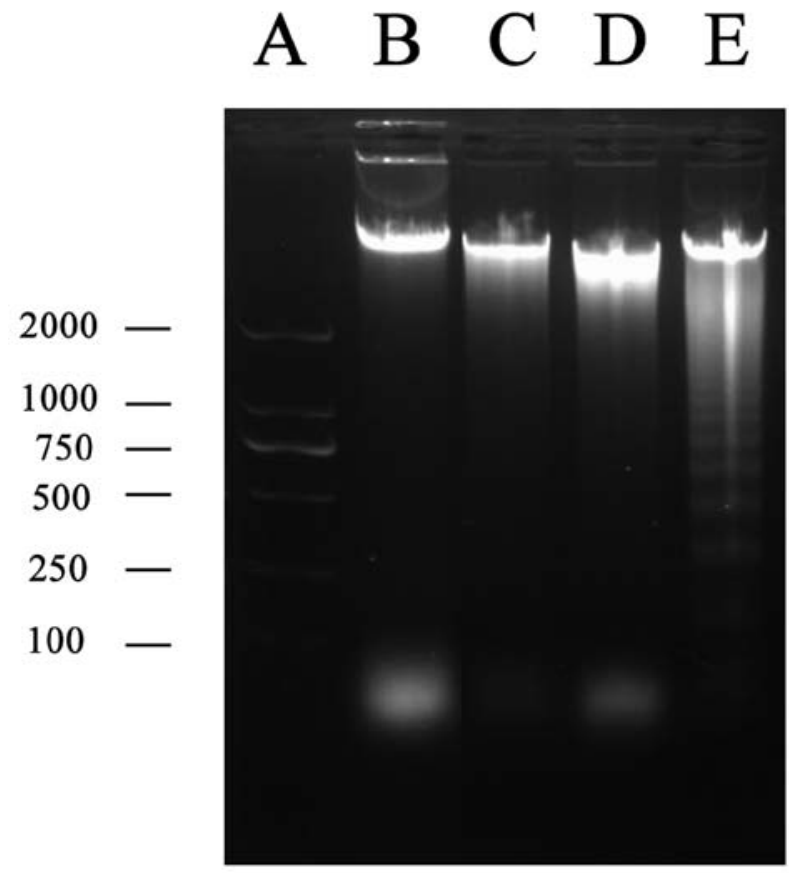

Figure 4. MCF-7/ADR cells treated with a combination of honokiol and VP-16 demonstrate clumping degradation of nuclear DNA. Internucleosomal DNA fragmentation was identified by DNA gel electrophoresis in MCF-7/ADR cells treated with honokiol $40 \mu \mathrm{g} / \mathrm{ml}$ (C) or combination drugs (D), respectively. No clear DNA ladders were detected in these two groups. Both $\mathrm{C}$ and $\mathrm{D}$ groups manifested clumping degradation of nuclear DNA. Blank control was used as negative control (B); HL-60 treated with VP-16 $20 \mu \mathrm{g} / \mathrm{ml}$, as positive control (E). DNA ladder 2000 was used as a marker (A). These results are representative of three independent experiments.

integrity (PI-positive), 39.07\% of cells were PI-positive (upper quadrants) and $6.16 \%$ were Annexin $\mathrm{V}$ positive and PI negative (lower right quadrant) (Fig. 6A).

We previously demonstrated that honokiol-induced necrotic cell death in MCF-7 cells was modulated by cyclophilin D (a major component of the mitochondrial permeability transition pore, CypD), which can be prevented by cyclosporin A (CsA, inhibitor of CypD) (9). Accordingly, we used Annexin V-FITC/PI assay to determine the effect of CsA on honokiol-induced necrotic cell death in MCF-7/ADR cells. Honokiol-induced necrotic cell death was reversed by $14.97 \%$ with pretreatment of $25 \mu \mathrm{M}$ CsA for $2 \mathrm{~h}$ (Fig. 6A). These results indicated honokiol-induced necrotic cell death in MCF-7/ADR was partly associated with CypD.

The above results provided substantial evidence for the original assumptions that honokiol at a higher dose $(40 \mu \mathrm{g} /$ $\mathrm{ml}$ ) induced dominant programmed necrotic cell death in MCF-7/ADR cells and could be prevented by CsA, which accords with that in the parallel cell line MCF-7 (9).

Honokiol and VP-16 combination activates complex cell death pathways. Honokiol $(40 \mu \mathrm{g} / \mathrm{ml})$ induced cell death with necrotic characteristics in MCF-7/ADR cells as demonstrated above. Consequently, we hypothesized the combination of honokiol would enhance the cytotoxic effect of VP-16 through additional necrotic cell death. To authenticate this hypothesis, several markers of cell death modality were analyzed, including
DNA ladder, morphological manifestations and Annexin V/ PI staining.

Characteristic DNA fragmentation detected by DNA ladder is a direct indication of the existence of apoptosis. We used DNA ladder to determine if apoptosis was the major cell death pathway for MCF-7/ADR cells treated with honokiol plus VP-16. As shown in Fig. 4, no DNA ladder but clumping degradation of nuclear DNA was detected in cells treated with honokiol plus VP-16, which indicated apoptosis was not the major cell death pathway (Fig. 4).

Further electron microscopy morphological examinations demonstrated cells treated with VP-16 plus honokiol displayed complex features composed of necrotic cell death (severe vacuolation and dilatation of mitochondria) (Fig. 5D and E) and apoptosis (chromatin condensation and margination) (Fig. 5F). Parts of cells treated with VP-16 exhibited early staged apoptotic manifestations, while most cells had normal morphological manifestations (Fig. 5B).

The effects of VP-16 combined with honokiol on induction of cell death were then examined with Annexin V-FITC/PI assay. Inhibition of cell viability was more efficient after incubation with honokiol plus VP-16 $(40.96 \pm 2.18 \%)$ than honokiol $(51.90 \pm 3.46 \%)(\mathrm{P}<0.05)$ (Fig. 6B). Honokiol alone induced MCF-7/ADR cell death with obvious characteristics of necrotic cell death as shown in Honokiol-induced programmed necrotic cell death in MCF-7/ADR cells, which is reversed by cyclosporin A. While treatment with combination of honokiol and VP-16 increased the ratio of cell death, including $37.48 \%$ of cells PI positive and $19.97 \%$ Annexin V-positive and PI-negative (Fig. 6A), which increased necrosis by $27.60 \%$ and apoptosis by $16.80 \%$ from basal level. Taken together, these results indicated that the combination treatment of honokiol plus VP-16 induced complex cell death including apoptosis and programmed necrotic cell death in MCF-7/ADR cells.

Combination of cyclosporin A and z-VAD-fmk shuts down the complex cell death pathways. Above data indicated: i) the combination treatment of VP-16 and honokiol induced programmed cell death containing apoptosis and necrotic cell death in MCF-7/ADR cells; ii) CsA reversed honokiolinduced programmed necrotic death in MCF-7/ADR cells. CsA and z-VAD-fmk were used separately or together to confirm whether caspase-dependent apoptosis and necrotic cell death constituted the complex cell death induced by honokiol plus VP-16. After CsA pretreatment, morphological examinations demonstrated that more cells exhibited apoptotic manifestations (Fig. 5G) than that shown in treatment of VP-16 plus honokiol (Fig. 5D-F), whereas still some cells exhibited necrotic manifestations. Moreover, Fig. 6A revealed honokiol plus VP-16-induced necrotic cell death was reversed by $19.97 \%$ with CsA, while apoptosis was reversed by z-VAD-fmk $13.40 \%$, but when pretreated with both CsA and z-VAD-fmk, honokiol plus VP-16-induced necrotic cell death and apoptosis were increasingly reversed by 26.85 and 15.67\%. Viable cells were increased after pretreated with CsA, z-VAD-fmk, or both $(79.02 \pm 8.12,75.79 \pm 6.41$ and $84.47 \pm 4.31 \%$, respectively) (Fig. 6B). Which indicates that honokiol plus VP-16 induced complex cell death was almost completely shut down by pretreatment with both CsA and z-VAD-fmk. These 


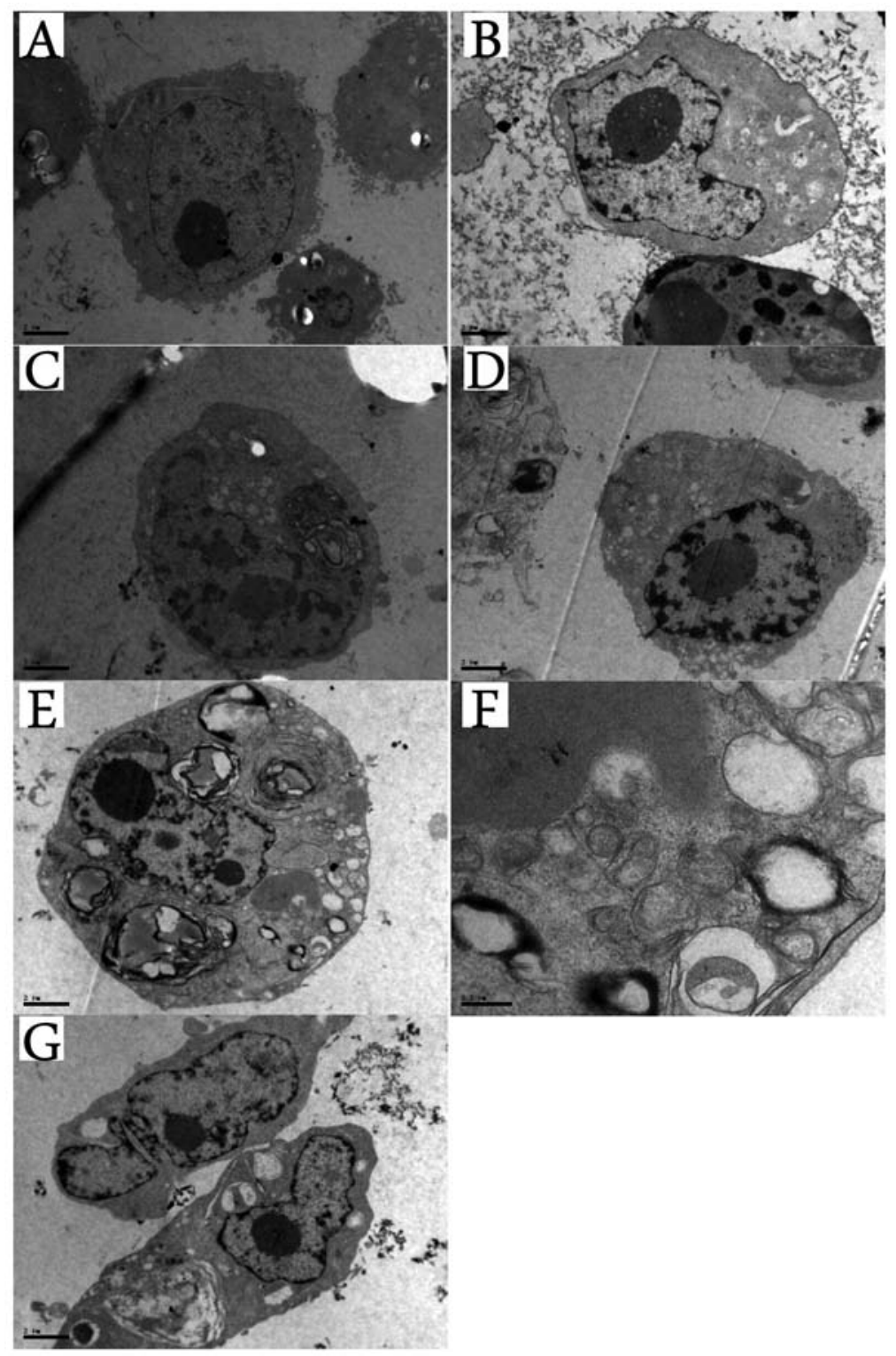

Figure 5. Combination of honokiol and VP-16 induces a complex death modality with dominant necrotic coupled with apoptotic morphology. (A) Control MCF-7/ADR; (B) $100 \mu \mathrm{g} / \mathrm{ml} \mathrm{VP-16-treated} \mathrm{cells} \mathrm{for} 6 \mathrm{~h}$, typical apoptotic appearances such as chromatin condensation and margination compared with control cells; (C) $40 \mu \mathrm{g} / \mathrm{ml}$ honokiol-treated cells with necrotic morphology, irregular clumping of chromatin with appearance of cleared nuclear domains, rounded mitochondria with disrupted internal structures, extensive cytoplasmic vacuolation and autophagic vacuoles containing membranous whorls; (D-F) honokiol plus VP-16 combination treated cells for $6 \mathrm{~h}$; (D) apoptotic appearance resemble that of B; (E) necrotic features similar to that in C; (F) high-power magnifications showing mitochondria with disrupted internal structures, cytoplasmic vacuolation and autophagic vacuoles; $(\mathrm{G})$ cells pretreated with $25 \mu \mathrm{M} \mathrm{CsA}$ for $2 \mathrm{~h}$ before combination treatment, more cells exhibited apoptotic manifestations than that in combination treatment of honokiol and VP-16.

results indicated combination treatment of VP-16 and honokiol induced programmed cell death contained caspase-dependent apoptosis and programmed necrotic cell death, which were prevented by CsA and z-VAD-fmk.

Honokiol blocks nuclear translocation of $N F-\kappa B$ induced by $V P-16$. Activated NF- $\mathrm{KB}$ binds to specific DNA sequences in target genes associated with anti-apoptotic effects or expression of multiple drug resistant proteins, such as $\mathrm{P}-\mathrm{gp}, \mathrm{Bcl}-2$, $\mathrm{Bcl}-\mathrm{xl}$ and xIAP. Constitutively activated NF- $\mathrm{KB}$ is associated with cell resistance to various chemotherapeutic agents. Nuclear translocation of NF- $\kappa \mathrm{B}$ is momentous in NF- $\kappa \mathrm{B}$ signal transduction pathway. Blocking nuclear translocation of NF- $\mathrm{kB}$ is a potential target in the reversal of chemoresis- tance. We used western blot analysis to explore the differences of NF- $\mathrm{BB}$ expression in nuclear and cytoplasm after VP-16 incubation with or without honokiol. Although no changes were detected in cytoplasmic NF- $\mathrm{KB}$, expressions of nuclear NF- $\kappa$ B were different between different treatments (Fig. 7A). Expression of nuclear NF- $\mathrm{\kappa B}$ was slightly increased after incubated with VP-16 for $2 \mathrm{~h}(1.16 \pm 0.02$-fold compared with control), but decreased after incubated with honokiol alone for $2 \mathrm{~h}(0.55 \pm 0.01$-fold $)$. And the expression of nuclear NF- $\mathrm{KB}$ after co-incubated with VP-16 and honokiol (0.95 \pm 0.03 -fold) was decreased compared to that of VP-16 treatment alone $(\mathrm{P}<0.001)$ (Fig. 7B). These results revealed that honokiol not only decreased the primarily enhanced nuclear expression of NF- $\mathrm{BB}$ in multi-drug resistant cell line MCF-7/ADR, but also 


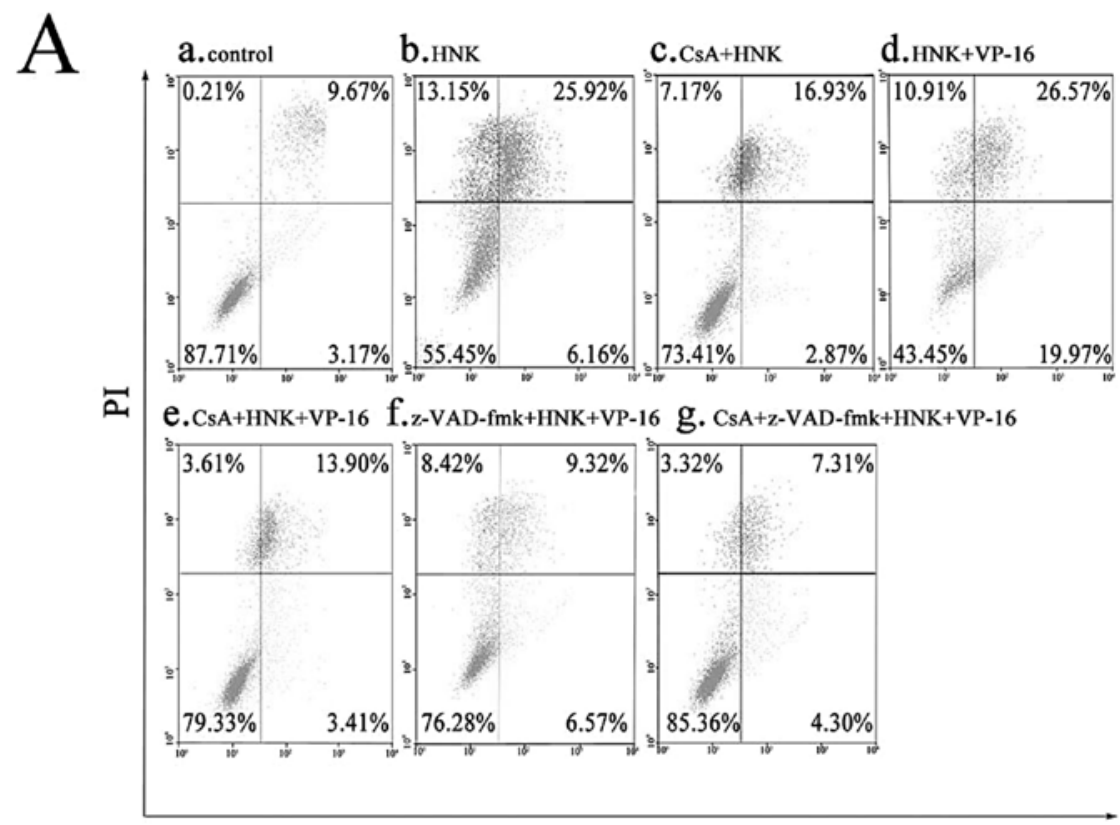

Annexin-V-FITC

B

Figure 6. Honokiol plus VP-16 induces complex cell death with dominant necrotic characteristics coupled with apoptotic features, which is reversed by pretreated with CsA, z-VAD-fmk or both. (A) Flow cytometric assays for phosphatidyl serine externalization or PI permeability; (B) viable cells (AV negative and PI negative cells) calculated from flow cytometric results; a, 0.1\% DMSO (vehicle control); b, cell treated with $40 \mu \mathrm{g} / \mathrm{ml}$ honokiol; c, honokiol (pretreated with CsA); d, VP-16 plus honokiol; e, VP-16 plus honokiol (pretreated with CsA); f, VP-16 plus honokiol (pretreated with z-VAD-fmk); g, VP-16 plus honokiol (pretreated with CsA and z-VAD-fmk). The drug concentrations and incubation time applied: honokiol $40 \mu \mathrm{g} / \mathrm{ml}$ for $6 \mathrm{~h}$; VP-16 $100 \mu \mathrm{g} / \mathrm{ml}$ for $6 \mathrm{~h}$; CsA $25 \mu \mathrm{M}$ for $2 \mathrm{~h}$; z-VAD-fmk $50 \mu \mathrm{M}$ for $30 \mathrm{~min}$. These results were representative of three independent experiments. The values are shown as mean $\pm \mathrm{SD}$. ${ }^{*} \mathrm{P}<0.001 \mathrm{vs}$. control; ${ }^{* *} \mathrm{P}<0.05 \mathrm{vs}$. honokiol-treated cells; ${ }^{~} \mathrm{P}<0.001$ vs. VP-16 plus honokiol treated.

reversed VP-16-induced nuclear translocation and activation of $\mathrm{NF}-\kappa \mathrm{B}$.

\section{Discussion}

Most previous studies concerning combination effect of honokiol with other chemotherapeutic agents only focused on 'therapeutic synergy' or 'therapeutic enhancement', which manifested as, at a given dose, honokiol strengthened cytotoxicity of other chemotherapeutic agents. But this phenomenon does not exactly signify synergism. It is perhaps composed of pure synergism, additive effect, or even moderate antagonism if the drugs at combination do not produce overlapping toxicity. Consequently, the evaluation of a drug combination as 'therapeutic synergy' seems subjective and lacks quantitative data. Accordingly, we use the combination index equation of Chou and Talalay (16) to quantitatively and 

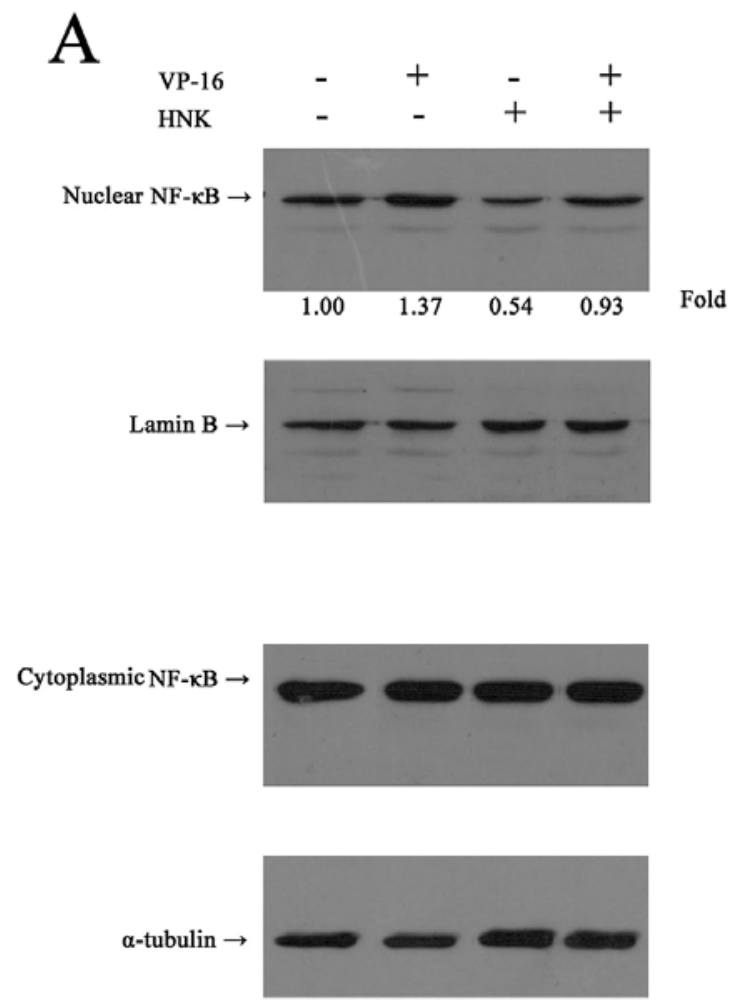

B

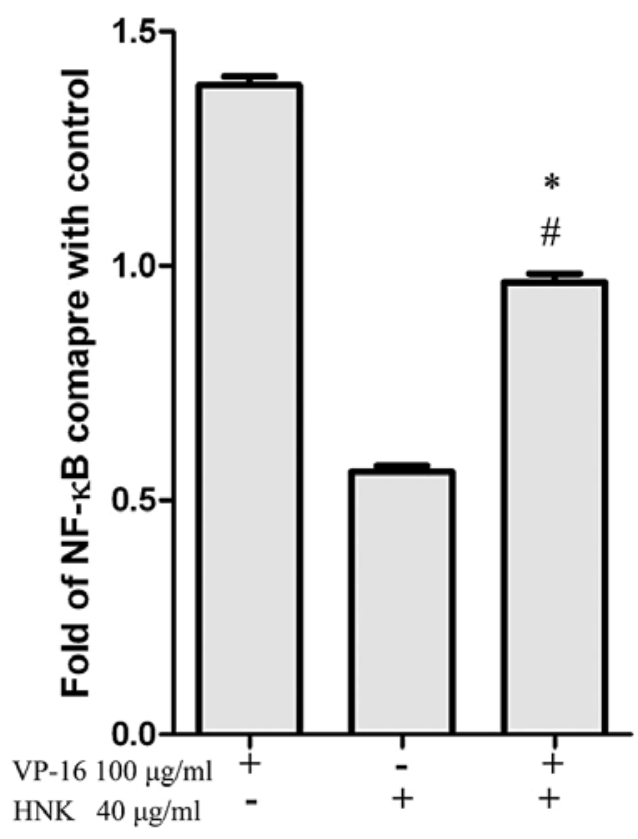

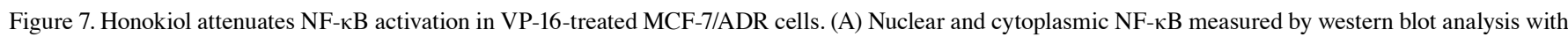
Lamin B and $\alpha$-tubulin as internal controls, respectively. (B) Relative folds of nuclear NF- $\mathrm{B}$ compared with negative control. These results are representative of three independent experiments. The values are shown as mean $\pm \mathrm{SD}$. ${ }^{*} \mathrm{P}<0.001 \mathrm{vs.}$ VP-16-treated cells; ${ }^{"} \mathrm{P}<0.001$ vs. honokiol-treated cells.

objectively calculate the real combination effects of honokiol with other chemotherapeutic agents in both sensitive and resistant cancer cell lines, solid and none-solid cancer cell lines.

Honokiol synergized ADM and taxol in breast carcinoma cell line MCF-7 and with DNR in acute promyelocytic leukemia cell line HL-60. Through evaluation of DRI, we found honokiol at slight toxic concentrations synergized the antitumor effects of ADM and taxol in MCF-7, synergized the antitumor effects of DNR in HL-60. In multidrug resistant cell lines MCF-7/ADR and HL-60/ADR, honokiol also synergized the antitumor effects of ADM, VP-16 or DNR as that shown in the calculation of CI and DRI values.

Multiple drug resistance refers to the phenomenon that tumor cells are resistant to various structural and functional different drugs. As we have demonstrated synergistic activity of honokiol with chemotherapeutic agents in MDR cell lines, we aimed to investigate its possible mechanisms, especially associated with overcoming multiple drug resistance. $\mathrm{P}$-gp is the first identified and most well studied ABC transporter, which catalyses the active efflux transport of various structurally unrelated therapeutic agents (19). Our previous report demonstrated at a lower concentration ( $20 \mu \mathrm{M}, 5 \mu \mathrm{g} / \mathrm{ml})$, honokiol enhances cytotoxic effect of ADM through downregulation of P-gp (2). These results provide substantial evidence for synergistic mechanism of honokiol at a lower concentration, but possible synergistic mechanism of honokiol at higher concentration is still in need of evaluation.

Programmed necrotic cell death (necroptosis) is one of the non-apoptotic mechanisms of cell death, which is also regu- lated by multiple signal transduction pathways and metabolic processes $(8,20-22)$. Honokiol induces programmed necrotic cell death associated with mitochondrial permeability transition pore in MCF-7 at the concentration $40 \mu \mathrm{g} / \mathrm{ml}$ as we previously reported (9). We presume honokiol also induces necrotic cell death in the parallel drug resistant cell line MCF-7/ADR and the subsequent research data in our present study support the above notion. All evidence including DNA ladder findings, flow cytometric analysis and electron microscopy morphological manifestations, are in conformity with those of MCF-7 (9). In agreement with MCF-7, CsA prevents this necrotic cell death induced by $40 \mu \mathrm{g} / \mathrm{ml}$ honokiol in MCF-7/ADR. These results provide substantial evidence for the original assumptions that honokiol $40 \mu \mathrm{g} / \mathrm{ml}$ induces necrotic cell death which can be prevented by CsA in multi-drug resistant cell line MCF-7/ADR.

The substantial pharmacological objective of chemotherapy is inducing tumor cell death. Most chemotherapeutic agents kill tumor cells through apoptosis pathway. Evasion of drug-induced apoptosis is a major barrier for the success of chemotherapy. Most research concentrates on obstructing Bcl-2 family members or associated signal signaling pathways to overcome resistance to apoptosis. Nonetheless, we consider simultaneous activating multiple death pathways may be another choice to overcome apoptosis-escape associated MDR. After demonstrating $40 \mu \mathrm{g} / \mathrm{ml}$ honokiol inducing necrotic cell death in MCF-7/ADR cells, we presume the mechanism of honokiol at a higher concentration synergizes conventional chemotherapy agents and overcomes MDR through additional necrotic cell death. We further assessed the synergistic mechanism of 


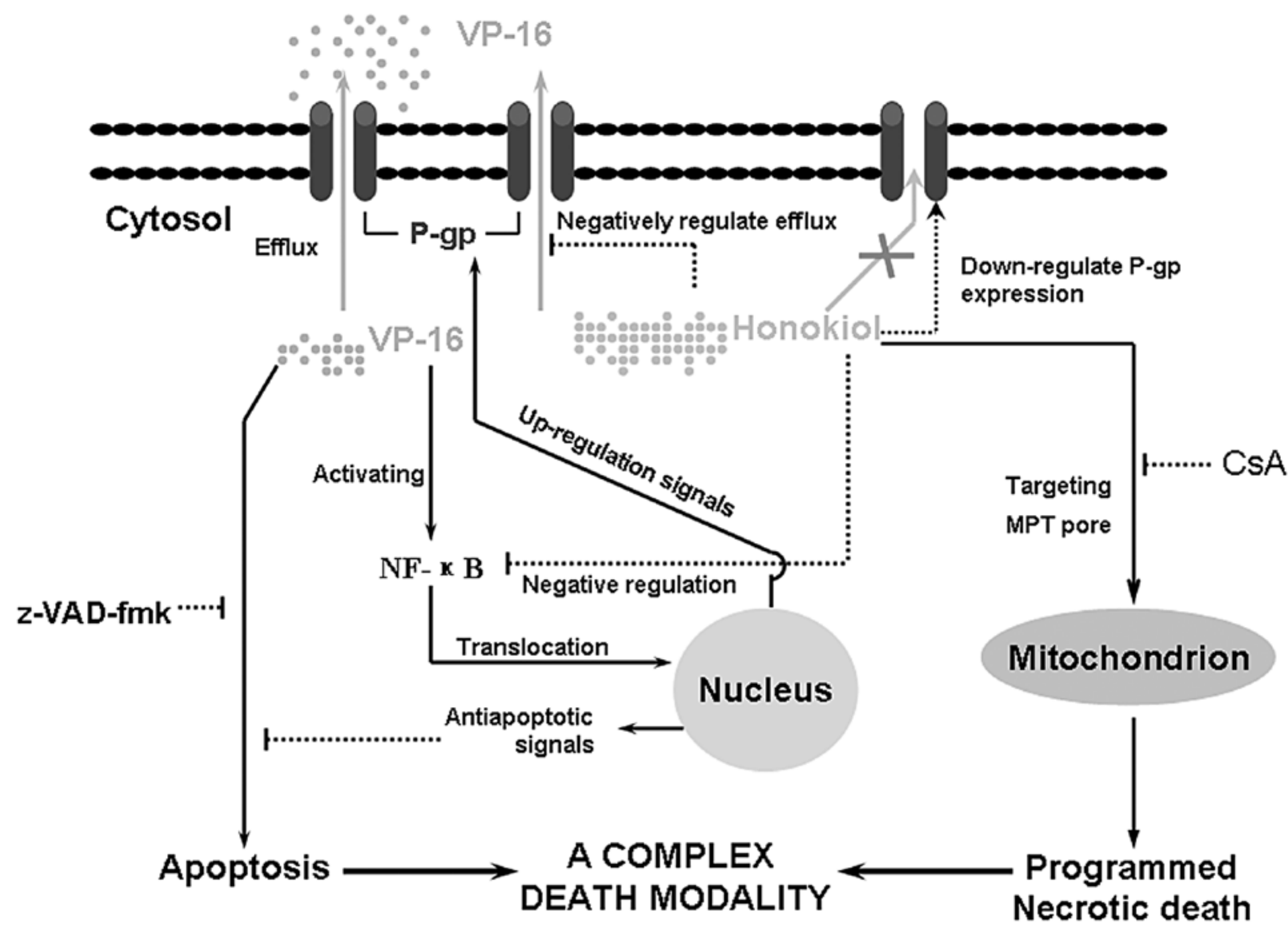

Figure 8. Possible mechanisms of honokiol leading to the synergistic effect and overcoming MDR.

honokiol $(40 \mu \mathrm{g} / \mathrm{ml})$ with VP-16 $(100 \mu \mathrm{g} / \mathrm{ml})$. Morphological manifestations revealed the complex cell death containing necrotic cell death and apoptosis. Flow cytometry analyzed Annexin V-FITC/PI also demonstrated both cell death pathways were activated after incubation with honokiol and VP-16. While pretreatment with z-VAD-fmk or CsA not only partly blocked apoptosis but also reversed necrotic cell death. Supposing that mitochondria permeability transition is a core step in both programmed necrotic cell death and apoptosis (23), it is understandable that $\mathrm{CsA}$, an inhibitor of CypD, has the potency to prevent both programmed necrotic cell death and apoptosis induced by honokiol plus VP-16. z-VAD-fmk is a pan-caspase inhibitor, which mainly blocks the cascade of caspase-dependent apoptosis. Consequently, the inhibition of early stage apoptosis by z-VAD-fmk can be readily explained. z-VAD-fmk can not inhibit honokiol induced necrotic cell death in MCF-7 cells (9), whereas it partly prevents necrotic cell death induced by combination of honokiol and VP-16. A possible explanation is that the combination treatment of honokiol and VP-16 activates some caspase associated pathways, which participate in both cascades of apoptosis and programmed necrotic death. The existence of caspase associated cross-talk between these two cell death modalities enable z-VAD-fmk to block both programmed necrotic death and apoptosis. Accordingly, we suppose that these two kinds of cell death constitute a more complex cell death modality and share some corporate signaling pathways. These experimental results support the original hypothesis that honokiol synergized the antitumor effect of VP-16 by inducing enhanced apoptosis and additional necrotic cell death.

Transcription factor NF- $\mathrm{B}$ critically regulates a variety of cell physiological and pathological processes $(24,25)$. Aberrant $\mathrm{NF}-\kappa \mathrm{B}$ activation takes part in development of the hallmarks of cancer (26). One of the most documented functions of NF- $\kappa \mathrm{B}$ is its capacity to modulate cancer cell chemoresistance through efflux of drugs and evasion from drug-induced apoptosis by inducing the expression of genes coding anti-apoptotic proteins (such as Bcl-2, Bcl-xl and xIAP) (27-29) and ABC families (such as P-gp) (30). Previous reports indicate honokiol suppresses activation of $\mathrm{NF}-\kappa \mathrm{B}$ and $\mathrm{NF}-\kappa \mathrm{B}-$ regulated gene expression by inhibition of nuclear translocation and transcriptional activity of NF- $\kappa \mathrm{B}$ responsive promoter (31-33). Honokiol downregulates the expression of $\mathrm{NF}-\kappa \mathrm{B}$-regulated anti-apoptotic and drug resistance gene products including Bcl-x, Bcl-2, cFLIP, IAP1, IAP2 (32) and P-gp. Our data indicate VP-16 can induce NF- $\kappa$ B activation in MCF-7/ADR cells, which accord with previous reports $(34,35)$. The data from western blots suggested that honokiol enhanced VP-16-induced apoptosis possibly via block of NF- $\kappa \mathrm{B}$ activation, which might lead to subsequent drug resistance and apoptosis tolerance. These results provide evidence for that honokiol by suppressing VP-16-induced NF- $\kappa \mathrm{B}$ activation partly contributes to the synergistic effect.

The mechanistic findings of this study are restricted to synergistic effect of honokiol with VP-16 in MCF-7/ADR. Combination effects of honokiol and VP-16 are conspicuously 
different in MCF-7/ADR (synergism) and parental cell line MCF-7 (antagonism). The possible mechanism and associated signal pathways underlying the above phenomenon are still under investigation in our research group.

Collectively, according to our previous report (2) and present results, we conclude that the possible mechanisms leading to the synergistic effect and overcoming drug resistance are: i) honokiol downregulates P-gp expression and negatively regulates efflux of chemotherapeutic agents; ii) honokiol is not the substrate of P-gp and keeps sensitivity towards MDR cancer cells; iii) honokiol plus VP-16 induces a very complex death modality composed of programmed necrotic cell death and apoptosis; iv) VP-16 activates NF- $\mathrm{kB}$ and subsequent drugresistance or apoptosis tolerance, whereas honokiol block it (Fig. 8).

In conclusion, our data demonstrate for the first time that honokiol synergistically enhanced cytotoxicity of frequentlyused chemotherapeutic agents in both sensitive and resistant cancer cell lines. Activating complex cell death pathways through enhanced apoptosis and additional programmed necrotic death may be the principal mechanism underlying the synergistic effect. These findings show a promising way to circumvent multidrug resistance and apoptosis tolerance, which make honokiol a promising novel anticancer drug especially in refractory cancers.

\section{Acknowledgements}

Dong $\mathrm{Xu}$ received research grants from National Natural Science Foundation of China (no. 30901741) and Zhejiang Provincial Natural Science Foundation of China (no.Y2080308); Jie Sun received research grants from National Natural Science Foundation of China (no. 81102012).

\section{References}

1. Hu X and Xuan Y: Bypassing cancer drug resistance by activating multiple death pathways - a proposal from the study of circumventing cancer drug resistance by induction of necroptosis. Cancer Lett 259: 127-137, 2008

2. Xu D, Lu Q and Hu X: Down-regulation of P-glycoprotein expression in MDR breast cancer cell MCF-7/ADR by honokiol Cancer Lett 243: 274-280, 2006.

3. Baguley BC: Multiple drug resistance mechanisms in cancer. Mol Biotechnol 46: 308-316, 2010.

4. Xu D, Tian W and Shen H: Curcumin prevents induced drug resistance: a novel function? Chin J Cancer Res 23: 218-223, 2011.

5. Gillet JP and Gottesman MM: Mechanisms of multidrug resistance in cancer. Methods Mol Biol 596: 47-76, 2010.

6. Gandhi L, Harding MW, Neubauer M, et al: A phase II study of the safety and efficacy of the multidrug resistance inhibitor VX-710 combined with doxorubicin and vincristine in patients with recurrent small cell lung cancer. Cancer 109: 924-932, 2007.

7. Ruff P, Vorobiof DA, Jordaan JP, et al: A randomized, placebocontrolled, double-blind phase 2 study of docetaxel compared to docetaxel plus zosuquidar (LY335979) in women with metastatic or locally recurrent breast cancer who have received one prior chemotherapy regimen. Cancer Chemother Pharmacol 64 763-768, 2009.

8. Kroemer G, Galluzzi L, Vandenabeele P, et al: Classification of cell death: recommendations of the Nomenclature Committee on Cell Death 2009. Cell Death Differ 16: 3-11, 2009.

9. Li L, Han W, Gu Y, et al: Honokiol induces a necrotic cell death through the mitochondrial permeability transition pore. Cancer Res 67: 4894-4903, 2007.

10. Xuan Y and $\mathrm{Hu} \mathrm{X}$ : Naturally-occurring shikonin analogues - a class of necroptotic inducers that circumvent cancer drug resistance. Cancer Lett 274: 233-242, 2009.
11. Guidicelli G, Chaigne-Delalande B, Dilhuydy MS, et al: The necrotic signal induced by mycophenolic acid overcomes apoptosis-resistance in tumor cells. PLoS One 4: e5493, 2009.

12. Ishitsuka K, Hideshima T, Hamasaki M, et al: Honokiol overcomes conventional drug resistance in human multiple myeloma by induction of caspase-dependent and -independent apoptosis. Blood 106: 1794-1800, 2005.

13. Wang Y, Yang Z and Zhao X: Honokiol induces paraptosis and apoptosis and exhibits schedule-dependent synergy in combination with imatinib in human leukemia cells. Toxicol Mech Methods 20: 234-241, 2010.

14. Wang T, Chen F, Chen Z, et al: Honokiol induces apoptosis through p53-independent pathway in human colorectal cell line RKO. World J Gastroenterol 10: 2205-2208, 2004.

15. Chen F, Wang T, Wu YF, et al: Honokiol: a potent chemotherapy candidate for human colorectal carcinoma. World J Gastroenterol 10: 3459-3463, 2004.

16. Chou TC and Talalay P: Quantitative analysis of dose-effect relationships: the combined effects of multiple drugs or enzyme inhibitors. Adv Enzyme Regul 22: 27-55, 1984.

17. Bijnsdorp IV, Giovannetti E and Peters GJ: Analysis of drug interactions. Methods Mol Biol 731: 421-434, 2011.

18. Battle TE, Arbiser J and Frank DA: The natural product honokiol induces caspase-dependent apoptosis in B-cell chronic lymphocytic leukemia (B-CLL) cells. Blood 106: 690-697, 2005.

19. Steinbach D and Legrand O: ABC transporters and drug resistance in leukemia: was P-gp nothing but the first head of the Hydra? Leukemia 21: 1172-1176, 2007.

20. Golstein P and Kroemer G: Cell death by necrosis: towards a molecular definition. Trends Biochem Sci 32: 37-43, 2007.

21. Vandenabeele P, Galluzzi L, Vanden Berghe T and Kroemer G: Molecular mechanisms of necroptosis: an ordered cellular explosion. Nat Rev Mol Cell Biol 11: 700-714, 2010.

22. Degterev A and Yuan J: Expansion and evolution of cell death programmes. Nat Rev Mol Cell Biol 9: 378-390, 2008.

23. Kinnally KW, Peixoto PM, Ryu SY and Dejean LM: Is mPTP the gatekeeper for necrosis, apoptosis, or both? Biochim Biophys Acta 1813: 616-622, 2011.

24. Oeckinghaus A, Hayden MS and Ghosh S: Crosstalk in NF-kappaB signaling pathways. Nat Immunol 12: 695-708, 2011.

25. Shih VF, Tsui R, Caldwell A and Hoffmann A: A single NFkappaB system for both canonical and non-canonical signaling. Cell Res 21: 86-102, 2011.

26. Hanahan D and Weinberg RA: Hallmarks of cancer: the next generation. Cell 144: 646-674, 2011.

27. Catz SD and Johnson JL: Transcriptional regulation of bcl-2 by nuclear factor kappa B and its significance in prostate cancer. Oncogene 20: 7342-7351, 2001.

28. Tamatani M, Che YH, Matsuzaki H, et al: Tumor necrosis factor induces Bcl-2 and Bcl-x expression through NFkappaB activation in primary hippocampal neurons. J Biol Chem 274: 8531-8538, 1999.

29. Dong QG, Sclabas GM, Fujioka S, et al: The function of multiple IkappaB : NF-kappaB complexes in the resistance of cancer cells to Taxol-induced apoptosis. Oncogene 21: 6510-6519, 2002.

30. Bentires-Alj M, Barbu V, Fillet M, et al: NF-kappaB transcription factor induces drug resistance through MDR1 expression in cancer cells. Oncogene 22: 90-97, 2003.

31. Arora S, Bhardwaj A, Srivastava SK, et al: Honokiol arrests cell cycle, induces apoptosis, and potentiates the cytotoxic effect of gemcitabine in human pancreatic cancer cells. PLoS One 6: e21573, 2011.

32. Ahn KS, Sethi G, Shishodia S, Sung B, Arbiser JL and Aggarwal BB: Honokiol potentiates apoptosis, suppresses osteoclastogenesis, and inhibits invasion through modulation of nuclear factor-kappaB activation pathway. Mol Cancer Res 4: 621-633, 2006.

33. Tse AK, Wan CK, Shen XL, Yang M and Fong WF: Honokiol inhibits TNF-alpha-stimulated NF-kappaB activation and NF-kappaB-regulated gene expression through suppression of IKK activation. Biochem Pharmacol 70: 1443-1457, 2005.

34. Arlt A, Vorndamm J, Breitenbroich M, et al: Inhibition of NF-kappaB sensitizes human pancreatic carcinoma cells to apoptosis induced by etoposide (VP16) or doxorubicin. Oncogene 20: 859-868, 2001.

35. Nakanishi $\mathrm{C}$ and Toi M: Nuclear factor-kappaB inhibitors as sensitizers to anticancer drugs. Nat Rev Cancer 5: 297-309, 2005. 